\title{
Audit of acute admissions of COPD: standards of care and management in the hospital setting
}

\author{
C.M. Roberts*, I. Ryland", D. Lowe*, Y. Kelly\#, C.E. Bucknall", M.G. Pearson*, on behalf of the audit \\ sub-committee of the standards of care committee of the British Thoracic Society and the Clinical \\ Effectiveness and Evaluation unit at the Royal College of Physicians
}

Audit of acute admissions of COPD: standards of care and management in the hospital setting. C.M. Roberts, I. Ryland, D. Lowe, Y. Kelly, C.E. Bucknall, M.G. Pearson, on behalf of the audit sub-committee of the standards of care committee of the British Thoracic Society and the Clinical Effectiveness and Evaluation unit at the Royal College of Physicians. (C) ERS Journals Ltd 2001.

ABSTRACT: Despite publication of several management guidelines for COPD, relatively little is known about standards of care in clinical practice.

Data were collected on the management of 1400 cases of acute admission with Chronic Obstructive Pulmonary Disease in 38 UK hospitals to compare clinical practice against the recommended British Thoracic Society standards. Variation in the process of care between the different centres was analysed and a comparison of the management by respiratory specialists and nonrespiratory specialists made.

There were large variations between centres for many of the variables studied. A forced expiratory volume in one second measurement was found in only $53 \%$ of cases. Of the investigations recommended in the acute management arterial blood gases were performed in $79 \%$ (interhospital range $40-100 \%$ ) of admissions and oxygen was formally prescribed in only 64\% (range 9-94\%). Of those cases with acidosis and hypercapnia $35 \%$ had no further blood gas analysis and only $13 \%$ received ventilatory support. Long-term management was also deficient with 246 cases known to be severely hypoxic on admission yet two-thirds had no confirmation that oxygen levels had returned to levels above the requirements for long-term oxygen therapy. Only $30 \%$ of current smokers had cessation advice documented.

To conclude, the median standards of care observed fell below those recommended by the guidelines. The lowest levels of performance were for patients not under the respiratory specialists, but specialists also have room for improvement. The substantial variation in the process of care between hospitals is strong evidence that it is possible for other centres with poorer performance to improve their levels of care.

Eur Respir J 2001; 17: 343-349.

\begin{abstract}
*Clinical Effectiveness and Evaluation unit, Royal College of Physicians, London and Whipps Cross Hospital, London, UK, " Aintree Chest Centre, University Hospital, Aintree, Liverpool, UK and Hairmyres Hospital, East Kilbride, UK.
\end{abstract}

Correspondence: C.M. Roberts, Chest Clinic, Whipps Cross Hospital, London, E11 1NR, UK.

Fax: 442085356709

Keywords: Audit

chronic obstructive lung disease

management guidelines

Received: April 272000

Accepted after revision October 32000
Chronic obstructive pulmonary disease (COPD) has a high prevalence and is one of the most common causes of emergency medical admission with a respiratory disorder in the UK $[1,2]$. Several national and international Thoracic Bodies have produced management guidelines [3-7] but relatively little is known about the standards of care of COPD as practised. Published studies encompass few hospitals, small patient numbers, and are not measured against nationally agreed standards. For example data from a sample of 100 cases from the West of Scotland suggested that care by respiratory specialists was better than that given by generalists [8]. A study from a single New Zealand hospital concluded that process of care was "adequate" measured against a local consensus view [9]. Following the launch of the British guidelines [7] the British Thoracic Society (BTS) performed an audit of the clinical practise of hospital care of patients admitted with acute exacerbations of COPD. The aims of the audit were to establish data on the current management of acute COPD in UK hospitals judged against the British guidelines and to identify differences in management between respiratory and nonrespiratory specialists.

\section{Methods}

Hospitals within the UK with acute Respiratory Medicine Departments were approached to participate in the study. All were asked to complete retrospective audit sheets from information held in case-note records on 40 consecutive admissions from September 1, 1997 with a clinical diagnosis of acute exacerbation of COPD as the admission criterion. The audit proforma developed by the BTS audit group, comprised 38 questions some with two or more stems covering the following areas of care: 1) background information and history prior to admission; 2) assessment and measurements on admission; 3) initial management; 4) continuing management and discharge, which included identifying the consultant responsible at the point of discharge as a 
respiratory specialist or other specialist; 5) follow-up in the three months after admission. The following standards were taken from the BTS guidelines for the five sections.

\section{Background information}

Forced expiratory volume in one second (FEV1) should be recorded to establish the diagnosis. When recorded as percent of predicted, an FEV $1>80 \%$ effectively excludes the diagnosis. Any record in the previous 5 years or in 3 months after admission was accepted.

\section{Assessment and measurements on admission}

Three symptoms should be recorded: increased dyspnoea, increased sputum volume, increased sputum purulence. The signs to be elicited include presence of purulent sputum, presence of peripheral oedema, temperature, tachypnoea. Urgent investigations should include arterial blood gas tensions noting the inspired inspiratory oxygen fraction $\left(F \mathrm{I}, \mathrm{O}_{2}\right)$, an initial peak flow and a chest radiograph.

\section{Initial management}

Guidelines recommend that oxygen therapy should be controlled (and the $\mathrm{FI}, \mathrm{O}_{2}$ be $\leqslant 28 \%$ ) until blood gas tensions are known.

Blood gas tensions should be repeated if initially patient is acidotic or hypercapnic, nebulized bronchodilators should be given, antibiotics and steroids administered where appropriate, ventilatory support (noninvasive positive pressure ventilation (NIPPV) or via endotracheal tube) should be considered in those with a $\mathrm{pH}<7.26$ and a rising arterial carbon dioxide tension $\left(\mathrm{Pa}, \mathrm{CO}_{2}\right)$.

\section{Continuing management and discharge}

The following are recommended: a peak flow chart should be started as soon as possible, FEV1 should be recorded before hospital discharge, arterial blood gases should be checked on air for those presenting with an initial low $\mathrm{Pa}_{\mathrm{a}} \mathrm{O}_{2}$. Discharge planning should include review of inhaler technique and smoking cessation advice to be given and documented for those still smoking prior to admission.

\section{Follow-up}

During later clinical stability formal reversibility testing should be undertaken, pulmonary rehabilitation considered whilst influenza vaccination is recommended for the elderly and those with severe COPD.

The audit proforma was accompanied by a detailed explanation of the reasoning for each question, possible answers, and guidance on where such information might be found within the case notes. Each centre nominated a consultant lead to be responsible for data quality and collection. A small payment was made on receipt of the completed audit forms. In order to check quality control five sets of case notes from each participating site were audited by a second observer usually a doctor in training from the same department.

\section{Statistics}

Results are expressed for all cases in the audit, usually as percentages for all hospitals combined. Percentages were also computed for individual hospitals: the variation in hospital performance is summarized by the inter-quartile range (IQR) and range of hospital percentages. Where data are incomplete this is clarified by the stating of the numerator and relevant denominator alongside the percentage calculated.

A comparative analysis was performed on the data collected for continuing management and discharge between those cared for by specialist physicians and nonspecialist physicians. P-values from Chi-squared tests of significance and 95\% confidence intervals (CI) for the difference between group percentages were calculated. This section of the analysis was limited to those aspects of patient care that might reasonably be expected to form the responsibility of the consultant in charge at the time of discharge. This was because the audit form asked specifically for this information and not the specialty under which the patient was admitted.

\section{Results}

Forty-three centres submitted audit data for analysis. Fourteen were University teaching hospitals and the remainder district hospitals. A total of 1,400 cases were available for analysis, median contribution 40 per centre, IQR 26-40. Dates of admission were known for all but one and $90 \%$ of admissions occurred during the months of September, October, and November 1997. Twenty-seven patients were included twice in the audit as re-admissions during the counting of consecutive cases. Thus, there were a total of 1,373 different patients included in all. For the analysis of the standards of care all 1,400 admissions are included and may be referred to as "cases".

Table 1 provides demographics and indices of disease severity at admission. Sixty-six per cent, (919/1400) of patients had a previous admission for COPD. Only $29 \%$ (400/1400) were first time admissions, with this information unknown in $6 \%$ of cases. Of the readmissions $6 \%$ (51/919) had been admitted within the preceding two weeks and 36\% (333/919) between 2 weeks and 4 months prior to the index admission. Measurement of FEV1 within the previous 5 yrs or subsequent 3 months was found in only 53\% (739) cases ((interhospital range $0-93 \%$ ), FEV1 as per cent pred was available in only $37 \%(514)$ ) and $5 \%(26)$ of all cases had a predicted value $>80 \%$. Median length of stay was 8 days (IQR $4-12$ ). Death from COPD within months of admission was recorded in 184/1342 cases (14\%).

\section{Assessment and measurement on admission}

The audit questionnaire examined, the documentation of three symptoms; "increased breathlessness"; 
Table 1.-Demographics and disease severity at admission

\begin{tabular}{|c|c|c|c|c|}
\hline & \multicolumn{2}{|c|}{ Sex } & \multicolumn{2}{|c|}{ Admission } \\
\hline & Male & Female & First & Re-admission \\
\hline Sex & $748(53)$ & $622(44)^{\#}$ & & \\
\hline Age & $72 \pm 9$ & $71 \pm 10$ & & \\
\hline FEV1 L & $1.09 \pm 0.58$ & $0.81 \pm 0.39$ & & \\
\hline & $0.94(0.66-1.31)$ & $0.71(0 . \overline{5} 5-1.00)$ & & \\
\hline FEV1 $\%$ pred & $\begin{array}{c}40 \pm 20 \\
35(25-49)\end{array}$ & $\begin{array}{c}42 \pm 19 \\
39(28-53)\end{array}$ & & \\
\hline Admission Status & & & $400(29)$ & $919(66)^{\bullet}$ \\
\hline Medications recorded at the time of admission & & & & \\
\hline Inhaled bronchodilator & & & $285(71)$ & $674(73)$ \\
\hline Long-acting bronchodilator & & & $30(8)$ & 175 (19) \\
\hline Inhaled steroid & & & $204(51)$ & $597(65)$ \\
\hline Systemic steroid & & & $110(28)$ & $344(37)$ \\
\hline One or more of the above & & & $327(82)$ & $845(92)$ \\
\hline Home nebulizer & & & $70(18)$ & $445(48)$ \\
\hline Home oxygen $^{+}$ & & & $23(6)$ & $268(29)$ \\
\hline Methylxanthine & & & $50(13)$ & $243(26)$ \\
\hline Antibiotic & & & $63(16)$ & $190(21)$ \\
\hline
\end{tabular}

Data presented as $\mathrm{n}(\%)$, mean \pm SD and median (interquartile range). ${ }^{\#}: 2 \%$ were unknown; ${ }^{\circ}: 6 \%$ admission details were unknown. ${ }^{+}$: of the 302 cases in which oxygen was reported, the type was stated as oxygen concentrator in 90 cases, and as a cylinder in 110 cases.

"increased sputum volume"; and "change in colour of sputum". Relevant entries were found in almost all cases for "increased breathlessness" but in only about two-thirds of cases for the other two symptoms. Respiratory rate was recorded in 70\% (982) of all cases, presence or absence of bilateral leg oedema in $66 \%$ (923), and temperature in 86\% (1209) (table 2).

A comment on the chest radiograph was recorded within the first $24 \mathrm{~h}$ in $65 \%$ (916) of cases and described infiltrates in a quarter of these. Arterial oxygen saturation $\left(\mathrm{Sa}_{\mathrm{a}} \mathrm{O}_{2}\right)$ was recorded by pulse oximetry in $76 \%(1061 / 1400)$ of admissions and was whilst breathing room air in 26\% (275). Arterial blood gases, were performed in 79\% (1109) of admissions. The inspired oxygen concentration was noted in $71 \%(786 / 1109)$ of these with $27 \%$ (296) breathing room air. In 19 cases an $\mathrm{S}_{\mathrm{a}, \mathrm{O}_{2}}$ of $\leqslant 92 \%$ was recorded but no arterial blood gas was performed.

\section{Initial management, within the first 24 h of admission}

The level of inspired oxygen was formally prescribed in $64 \%(886 / 1375)$ of cases (interhospital variation $9-94 \%$, IQR $53-77 \%$ ). It was more likely to be formally prescribed if the $\mathrm{Sa}_{\mathrm{a}} \mathrm{O}_{2}$ measured by pulse oximetry was $\leqslant 92 \%$. The distinction by level of $\mathrm{Pa}, \mathrm{O}_{2}$ was less obvious.

Repeat arterial blood gases were performed in $34 \%$, (371) of cases (interhospital range $0-62 \%$, IQR

Table 2. - Assessments and measurements on admission

\begin{tabular}{|c|c|c|c|c|c|c|c|c|c|}
\hline \multirow{2}{*}{$\begin{array}{l}\text { Assessment or measurement } \\
\text { made on admission }\end{array}$} & \multirow[b]{2}{*}{ n $(\%)$} & \multicolumn{2}{|c|}{ Interhospital variation } & \multirow{2}{*}{$\begin{array}{l}\text { Symptom present } \\
\text { reported } \mathrm{n}(\%)\end{array}$} & \multicolumn{5}{|c|}{ Overall summary statistics for patients } \\
\hline & & IQR \% & range $\%$ & & Mean & $\mathrm{SD}$ & Median & IQR & Range \\
\hline Increased breathless & $1347(96)$ & $93-100$ & $83-100$ & $1299(96)$ & & & & & \\
\hline Increased sputum volume & $987(70)$ & $52-85$ & $12-100$ & 574 & & & & & \\
\hline Change in colour & $948(68)$ & $53-82$ & $9-100$ & $502(53)$ & & & & & \\
\hline Bilateral leg oedema & $923(66)$ & $52-77$ & $9-97$ & $348(38)$ & & & & & \\
\hline $\begin{array}{l}\text { Comment on the chest } \\
\text { radiograph }\end{array}$ & $916(65)$ & $53-78$ & $0-98$ & $242(26)$ & & & & & \\
\hline Respiratory rate bpm & $982(70)$ & $60-86$ & $27-100$ & & 27 & 7 & 26 & $22-30$ & $10-60$ \\
\hline Temperature ${ }^{\circ} \mathrm{C}$ & $1209(86)$ & $85-97$ & $37-100$ & & 36.7 & 0.8 & 36.6 & $26.2-37.2$ & $34.0-40.0$ \\
\hline Peak flow $\mathrm{L} \cdot \mathrm{min}^{-1}$ & $648 *(46)$ & $30-55$ & $0-88$ & & 47 & 71 & 140 & $100-185$ & $10-460$ \\
\hline $\mathrm{Sa}_{\mathrm{a}, \mathrm{O}_{2}} \%$ & $1061(75)$ & $65-91$ & $5-100$ & & 91 & 8 & 94 & $89-96$ & $46-100$ \\
\hline $\begin{array}{l}\mathrm{pH} \\
P \mathrm{a}, \mathrm{CO}_{2} \mathrm{kPa} \\
P \mathrm{a}, \mathrm{O}_{2} \mathrm{kPa}\end{array}$ & $1109(79)$ & $73-90$ & $40-100$ & & $\begin{array}{r}7.39 \\
6.21 \\
10.31\end{array}$ & $\begin{array}{l}0.9 \\
2.18 \\
5.0\end{array}$ & $\begin{array}{l}7.40 \\
5.70 \\
9.01\end{array}$ & $\begin{array}{l}7.36-7.45 \\
4.81-6.91 \\
7.50-11.32\end{array}$ & $\begin{array}{l}6.89-7.80 \\
1.56-21.88 \\
3.30-48.40\end{array}$ \\
\hline
\end{tabular}

IQR: interquartile range; bpm: beats per minute. $S \mathrm{a}, \mathrm{O}_{2}$ : arterial oxygen saturation; $P_{\mathrm{a}, \mathrm{CO}_{2}}$ : arterial carbon dioxide tension; $P a, \mathrm{O}_{2}$ : arterial oxygen tension. *: 114 of these the actual value was marked "unrecordable". Statistical summary is for the 534 with values. 
$19-44 \%$ ), within $24 \mathrm{~h}$ of admission. They were more likely to be repeated in the acidotic patient.

Nebulized bronchodilators were documented as given in 91\% (1267/1400) of admissions. A $\beta_{2}$-agonist was used with an anticholinergic in 17\% (979/1267) of cases, a $\beta_{2}$-agonist alone in $17 \%$ (215) and an anticholinergic alone in $2 \%$ (28) whilst in $4 \%$ the type was unknown. Systemic steroids and antibiotics were given to the majority of patients.

Assisted ventilation (either invasive positive pressure ventilation (IPPV) or NIPPV) was used in $3 \%$ of cases (hospital range $0-11 \%$, IQR $0-5 \%$ ). Frequency of use was unaffected by first or re-admission but was more likely to be used in the acidotic patient (table 3 ).

\section{Continuing management}

A chart peak flow record to assess reversibility was kept in only a half of cases and a third overall had neither a peak flow chart or evidence of FEV1 recorded within 5 yrs or 3 months after the admission. Inhaler technique was infrequently assessed and smoking cessation advice rarely given and documented in the case notes. Documentation of vaccination advice recommendation of pulmonary rehabilitation and formal reversibility testing was poor.

In the first time admissions there were higher rates of

Table 3. - Initial management within $24 \mathrm{~h}$ of admission

\begin{tabular}{|c|c|}
\hline \multicolumn{2}{|c|}{ Formal prescription of level of inspired oxygen } \\
\hline Overall & 64 (886/1375 known) \\
\hline$S_{\mathrm{a}, \mathrm{O}_{2}} \leqslant 92$ & $75(328 / 439)$ \\
\hline$>92$ & $62(377 / 613)$ \\
\hline$P \mathrm{a}, \mathrm{O}_{2}<8 \mathrm{kPa}$ & $76(269 / 355)$ \\
\hline $8-9.99 \mathrm{kPa}$ & $71(231 / 326)$ \\
\hline $10+\mathrm{kPa}$ & $68(282 / 417)$ \\
\hline \multicolumn{2}{|l|}{ Repeat arterial blood gases } \\
\hline Overall & $\begin{array}{c}34 \text { (371/1109 done } \\
\text { on admission) }\end{array}$ \\
\hline$P \mathrm{a}, \mathrm{CO}_{2}>6.0 \mathrm{kPa}$ & $49(225 / 456)$ \\
\hline$\leqslant 6.0 \mathrm{kPa}$ & $22(144 / 642)$ \\
\hline $\mathrm{pH}<7.35$ & $63(141 / 224)$ \\
\hline $7.35+$ & $26(224 / 861)$ \\
\hline$P \mathrm{a}, \mathrm{CO}_{2}>6.0 \mathrm{kPa}$ & \\
\hline$\& \mathrm{pH}<7.35$ & $65(128 / 197)$ \\
\hline \multicolumn{2}{|c|}{ Assisted ventilation IPPV NIPPV } \\
\hline Overall & $3(40 / 1400)$ \\
\hline First COPD & $3(23 / 919)$ \\
\hline Re-admission & $3(10 / 400)$ \\
\hline$P \mathrm{a}, \mathrm{CO}_{2}>6.0 \mathrm{kPa}$ & $7(34 / 456)$ \\
\hline$\leqslant 6.0 \mathrm{kPa}$ & $1(4 / 642)$ \\
\hline $\mathrm{pH}<7.26$ & $15(11 / 72)$ \\
\hline $7.26-7.34$ & $11(16 / 152)$ \\
\hline $7.35+$ & $1(11 / 861)$ \\
\hline$P a, C_{2}>6.0 \mathrm{kPa}$ & \\
\hline$\& \mathrm{pH}<7.35$ & $13(25 / 197)$ \\
\hline \multicolumn{2}{|l|}{ Medication } \\
\hline Nebulized bronchodilator & $91(1267 / 1400)$ \\
\hline Steroids & $85(1183 / 1400)$ \\
\hline Antibiotics & $80(115 / 1400)$ \\
\hline
\end{tabular}

Data presented as $\%$ (absolute fraction); $S_{\mathrm{a}, \mathrm{O}_{2}}$ : arterial oxygen saturation. $\mathrm{Pa}_{\mathrm{a}} \mathrm{O}_{2}$ : arterial oxygen tension; $\mathrm{Pa}_{\mathrm{a}} \mathrm{CO}_{2}$ : arterial carbon dioxide tension; IPPV: invasive positive pressure ventilation; NIPPV: noninvasive positive pressure ventilation. checking inhaler technique (28 versus 16\%) and of giving smoking cessation advice to current smokers (34 versus $28 \%$ ). For those with previous admissions there were higher rates in the recording of FEV1 (58 versus 47\%) reversibility testing (bronchodilators: 29 versus $25 \%$, steroids: 8 versus $6 \%$ ), vaccination advice (4.9 versus $4.3 \%)$ and pulmonary rehabilitation advice $(3.2$ versus $2.0 \%$ ). Rates for outpatient follow-up were identical These differences are not unexpected and are of little clinical significance (table 4).

A $\mathrm{Pa}, \mathrm{O}_{2}$ on admission of $<7.3 \mathrm{kPa}$ was documented in 246 cases and few of these had a subsequent $\mathrm{Pa}, \mathrm{O}_{2}$ $>7.3 \mathrm{kPa}$ whilst breathing room air recorded in the case notes. Eighteen per cent (254) received oxygen when discharged stated as a concentrator in 111 cases and cylinder in 90 . This included 68 of the cases with an admission $\mathrm{Pa}, \mathrm{O}_{2}<7.3 \mathrm{kPa}$.

Out of 797 given outpatient follow-up 57\% (458) attended, 23\% (181) did not, 8\% (66) were readmitted and no information was available for the remaining $12 \%$. At the time of discharge $43 \%(602 / 1400)$ cases were under the care of a Chest Physician, 20\% (277) under a Geriatrician and 32\% (450 cases) under another speciality physician.

Comparison of respiratory and nonrespiratory specialist care

Respiratory specialists were more likely to record FEV1, chart peak expiratory flow (PEF), check inhaler technique, give smoking cessation advice, prescribe more medications at discharge, and arrange follow-up.

The severity of COPD when a measured FEV1 was available was compared between the two managed groups using a two-sample t-test. For male cases FEV1 (L) Respiratory specialists $1.07 \pm 0.59$, nonRespiratory specialists $1.09 \pm 0.54 \mathrm{p}=0.74, \mathrm{CI}-0.1-0.1$. FEV $1 \%$ pred value $39 \%$ and $41 \%$ respectively, $\mathrm{p}=0.43$, CI $-7-3 \%$. For female cases the more severe cases were biased towards the Respiratory specialists. For example FEV1 Respiratory specialists $0.78 \pm 0.38$, and non-Respiratory specialists $0.86 \pm 0.40$ $\mathrm{p}=0.07$, CI $-0.2-0.1 \mathrm{~L}$. As \% pred, Respiratory specialists $38 \%$ and non-Respiratory specialists $47 \%$, $\mathrm{p}=0.002$, CI $-14-3 \%$ (table 5$)$.

\section{Discussion}

This audit of the management of 1,400 cases of COPD admitted to hospitals throughout the UK has demonstrated deficiencies in standards of care measured against the BTS management guidelines as well as wide variations of process of care between hospitals that cannot be explained by known case-mix variables. Nearly half did not have objective confirmation of the diagnosis documented. Investigations recommended to optimize emergency management were often not performed, and later interventions that might influence the prognosis of the disease were not made (tables 3 and 4). Patients who at the time of discharge were under the responsibility of a respiratory specialist were more likely to have the severity of their disease documented, 


\begin{tabular}{|c|c|c|c|}
\hline & \multirow[b]{2}{*}{ n $(\%)$} & \multicolumn{2}{|c|}{ Hospital Variation } \\
\hline & & IQR \% & Range $\%$ \\
\hline PEF chart record & $710(51)$ & $28-68$ & $5-93$ \\
\hline FEV1 or PEF recorded & $988(71)$ & $58-84$ & $26-93$ \\
\hline Inhaler technique assessed & 241/1218 (20) & $4-26$ & $0-90$ \\
\hline \multicolumn{4}{|l|}{ Smoking cessation advice given: } \\
\hline to smokers & $134 / 445(30)$ & $14-45$ & $0-75$ \\
\hline to exsmokers in last 3 months & 7/64 (11) & $0-0$ & $0-50$ \\
\hline$P a, O_{2}>7.3 \mathrm{kPa}$ on air at any time & $455(33)$ & $18-48$ & $0-78$ \\
\hline OP follow-up & $797 / 1272(63)$ & $50-80$ & $22-94$ \\
\hline Vaccination advice given & $65(5)$ & $0-7$ & $0-21$ \\
\hline Pulmonary rehabilitation recommended & $39(3)$ & $0-3$ & $0-39$ \\
\hline Reversibility to bronchodilator tested & 378 (27) & $6-38$ & $0-86$ \\
\hline Steroid reversibility tested & $96(7)$ & $0-11$ & $0-44$ \\
\hline \multicolumn{4}{|l|}{ Discharge medication } \\
\hline Inhaled bronchodilator & $899(64)$ & $48-80$ & $28-100$ \\
\hline Long-acting bronchodilator & $209(15)$ & $5-18$ & $0-69$ \\
\hline Inhaled steroid & $779(56)$ & $45-68$ & $14-84$ \\
\hline Oral steroid & $803(57)$ & $47-71$ & $7-80$ \\
\hline Home nebulizer & $536(38)$ & $30-48$ & $0-86$ \\
\hline Home oxygen* & $254(18)$ & $10-25$ & $3-40$ \\
\hline Theophylline & $340(24)$ & $15-35$ & $0-50$ \\
\hline Antibiotics & $493(35)$ & $29-40$ & $5-78$ \\
\hline
\end{tabular}

*: Stated as concentrator in 105 cases and as cylinder in 90. PEF: peak expiratory flow; FEV1: forced expiratory volume in one second; $\mathrm{Pa}, \mathrm{O}_{2}$ : arterial oxygen tension; OP: outpatient.

to be receiving more medication at the time of discharge, and to have follow-up arrangements in place (table 5). There are few other published audits of standards of care in COPD with which to compare these findings [8-10] and none as comprehensive, including such large patient numbers and varied sample of hospitals. This current study is unique in measuring process of care against national guidelines for the management of COPD [7]. Similar variation in standards of care, has previously been linked to regional differences in outcome and death of patients with COPD [10].

The audit inclusion criterion was a clinical diagnosis of COPD at discharge. The BTS guidelines recommend confirmation of clinical diagnosis by spirometry. Whilst this simple investigation is available in every hospital and the audit protocol accepted an FEV1 recorded within the 5 yrs prior to admission or in the 3 months following admission, only $53 \%$ of cases had this documented. In only $37 \%$ (514) of all cases was this available as a percentage of the predicted mean value that is used to classify the severity of the condition. Of these $26(5 \%)$ had a value $>80 \%$ pred i.e. did not have COPD by the BTS criteria but still had this diagnostic label at discharge. The peak expiratory flow was recorded in $46 \%$ of cases on admission and a chart record vital to assess therapeutic response was kept in just $51 \%$ of cases. A formal reversibility test to bronchodilators or steroids was documented in $27 \%$ and $7 \%$ of cases respectively. Chest physicians were more likely to have confirmed the diagnosis of COPD than other specialists ( 71 versus $41 \%$ table 5). It is of concern that some clinicians do not appear to accept the need to confirm a clinical impression with a diagnostic test.

\section{Initial assessment}

There are a number of investigations recommended in the BTS guidelines that assist in the immediate management of admissions with acute deterioration in COPD. These include arterial blood gas analysis, chest radiograph, and peak flow measurement. These were documented in $79 \%, 65 \%$, and $46 \%$ of cases respectively with wide interhospital variation. For example a comment on the chest radiograph was recorded in $98 \%$ of cases in one centre and in no cases in another. Such wide differences points to poor clinical practice or inadequate case note records.

The variability between centres in recording arterial blood gas analysis was $40-100 \%$ (IQR 73-90\%) A formal prescription specifying inspired oxygen level was documented in only $64 \%$ of cases with a huge interhospital variation $(9-94 \%$ IQR $53-77 \%)$. Type II respiratory failure is a fairly common and treatable sequel to acute exacerbations of COPD however, of those with acidosis and hypercapnoea, over one-third failed to receive follow-up arterial blood gas analysis to monitor progress and only $13 \%$ received ventilatory support. This failure of management may suggest a nihilistic approach and occurred in spite of the good evidence that even in severe COPD the outcome following interventions for acute deteriorations is good [11].

\section{Long-term planning}

Long-term oxygen therapy and smoking cessation are proven interventions that may extend life expectancy in patients with COPD [12-15]. A 
Table 5. - Differences in the management of patients under the care of Respiratory Physicians $(n=602)$ and nonrespiratory specialists $(n=759)$ at the time of discharge

\begin{tabular}{|c|c|c|c|c|c|}
\hline Comparison made & Chest Physician \% & Non-specialist $\%$ & Chi-squared* & p-value & $95 \% \mathrm{CI}$ \\
\hline \multicolumn{6}{|l|}{ Inpatient Care } \\
\hline FEV1 recorded & 70 & 40 & 127.4 & $<0.001$ & $26-36$ \\
\hline FEV1 \% pred. & 49 & 27 & 69.2 & $<0.001$ & $17-27$ \\
\hline PEF chart & 61 & 44 & 35.8 & $<0.001$ & $6-17$ \\
\hline Inhaler technique & 21 & 14 & 12.1 & $<0.001$ & $4-13$ \\
\hline Smoking advice to current smokers & 36 & 26 & 4.6 & 0.03 & $1-18$ \\
\hline \multicolumn{6}{|l|}{ Discharge Medications Prescribed } \\
\hline Inhaled bronchodilator & 66 & 65 & 0.2 & 0.64 & $-4-6$ \\
\hline Inhaled long acting $\beta$-agonist & 20 & 12 & 16.1 & $<0.001$ & $4-12$ \\
\hline Inhaled steroid & 61 & 53 & 7.8 & 0.005 & $2-13$ \\
\hline Oral steroid & 61 & 56 & 4.3 & 0.04 & $0-11$ \\
\hline Home nebulizer & 49 & 31 & 43.1 & $<0.001$ & $12-23$ \\
\hline Home oxygen & 24 & 14 & 20.9 & $<0.001$ & $6-14$ \\
\hline Theophylline & 28 & 22 & 7.0 & 0.008 & $2-11$ \\
\hline Antibiotics & 36 & 36 & 0.06 & 0.81 & $-5-6$ \\
\hline \multicolumn{6}{|l|}{ Discharge plans } \\
\hline Follow-up arranged & 73 & 46 & 0.06 & $<0.001$ & $22-33$ \\
\hline Reversibility to BD & 33 & 23 & 14.4 & $<0.001$ & $4-14$ \\
\hline Reversibility to steroids & 10 & 4 & 19.2 & $<0.001$ & $3-9$ \\
\hline Vaccination advice & 5 & 4 & 1.2 & 0.27 & $-1-4$ \\
\hline Pulmonary rehabilitation & 5 & 1 & 23.3 & $<0.001$ & $3-6$ \\
\hline
\end{tabular}

Comparisons made using the Chi-squared test for $2 \times 2$ tables. Case numbers for inhaler technique and for smoking advice were lower due to exclusions. 95\% CI: 95\% confidence intervals; FEV1: forced expiratory volume in one second; PEF: peak expiratory flow; BD: bronchodilator.

$P$ a, $\mathrm{O}_{2}<7.3 \mathrm{kPa}$ was recorded in 246 cases at admission but only 15 of these $(6 \%)$ had a subsequent recorded $\mathrm{Pa}, \mathrm{O}_{2}$ of $>7.3 \mathrm{kPa}$ whilst breathing room air during the recovery phase of their admission or at subsequent clinic follow-up. Sixty-eight of the 246 were discharged on home oxygen and may have had prior oxygen assessments but no further investigation was made in the remaining $66 \%$. Smoking cessation advice was formally recorded as given in just $30 \%$ of current smokers and $11 \%$ of those who claim to have stopped within the preceding 3 months and who are known to be at serious risk of relapse. There is good evidence that smoking cessation strategies involving combinations of nicotine replacement greatly enhance success and should be made known to patients [16]. Whilst such advice may have been previously offered, these examples suggest less than optimal intervention care by physicians.

\section{Comparison with other studies}

Previous studies [8, 17, 18] in the management of patients with COPD and asthma have suggested respiratory specialists are more likely to provide better care than nonrespiratory medical specialists. This audit confirms these findings (table 4). Nevertheless patients under the care of chest teams still received care that appears to fall short of the optimum.

There are limitations to this study that require discussion. A high proportion of admissions were not the first inpatient episode for these cases and some of the absent documentation of interventions may have been made previously. A retrospective audit of case notes will inevitably contain some inaccuracies and depends upon the case note recording by doctors. In medico-legal terms absence of documentation implies absence of process. Quality of collected data depended upon those completing the audit forms and several levels of control were instituted. The power of the study comes from the large sample size and the number and variety of contributing centres. Results from this study will help to form a future COPD audit tool which will be brief and have easily collectable data, reproducible from one hospital centre to another, designed for routine prospective use in hospital medical departments.

\section{Implications for the future}

The fact that some hospitals do achieve highly when assessed against the BTS guidelines shows that targets are practical and attainable. Attention should be focused on disseminating good practise and examining reasons for poor process in hospitals with lower achievements. Better process may be a surrogate for better outcomes $[19,20]$ and process itself may be used as a surrogate of outcome in chronic medical disorders [21].

These data reflect the performance of hospitals and not of individuals. Each hospital in this audit received an individual report showing its performance against national averages. This form of benchmarking can be easily understood by medical and nonmedical staff [22]. Poorly performing units should examine data recording, staffing, organizational issues as well as management protocols and clinical competence. 


\section{References}

1. Anderson HR, Esmail A, Hollowell J, Littlejohns P, Strachan D. Epidemiologically based needs assessment: lower respiratory disease. London: Department of Health, 1993.

2. Pearson MG, Littler J, Davies PDO. An analysis of medical workload by speciality and diagnosis in Mersey: evidence of a specialist to patient mismatch. J R Coll Phys 1994; 28: 230-234.

3. Canadian Thoracic Society Workshop Group. Guidelines for the assessment and management of chronic obstructive pulmonary disease. Can Med Assoc J 1992; 147: $420-428$.

4. American Thoracic Society. Standards for the diagnosis and care of patients with chronic obstructive pulmonary disease. Am J Respir Crit Care Med 1995; 152: S77-121.

5. Siafakas NM, Vermeire P, Pride NB, et al. Optimal assessment and management of chronic obstructive pulmonary disease (COPD). Eur Respir J 1995; 8: $1398-1420$.

6. Chronic bronchitis and chronic obstructive pulmonary disease: Finnish national Guidelines for prevention and Treatment 1998-2007. Respir Med 1999; 93: $297-332$.

7. BTS guidelines for the management of Chronic Obstructive Pulmonary Disease. Thorax 1997; 52: $\mathrm{S} 1-28$.

8. Angus RM, Murray S, Kay JW, Thomson NC, Patel KR. Management of chronic airflow obstruction: differences in practice between respiratory and general physicians. Respir Med 1994; 88: 493-497.

9. Neill AM, Epton MJ, Martin IR, Drennan CJ, Town GI. An audit of the assessment and management of patients admitted to Christchurch Hospital with chronic obstructive pulmonary disease. $N$ Zealand Med J 1994; 107: 365-367.

10. Tuuponen $\mathrm{T}$, Keistinen $\mathrm{T}$, Kivela S. Regional differences in long-term mortality among hospitaltreated asthma and COPD patients. Scans J Soc Med 1997; 25: $238-242$.

11. McNally E, Fitzpatrick M, Bourke S, Costello R,
McNicholas WT. Reversible hypercapnia in acute exacerbations of chronic obstructive pulmonary disease. Eur Respir J 1993; 6: 1353-1356.

12. Nocturnal Oxygen Therapy Trial Group. Continuous or nocturnal oxygen therapy in hypoxaemic chronic obstructive pulmonary disease. A clinical trial. Ann Int Med 1980; 93: 391 - 398.

13. Medical Research Council Working Group. Long term domiciliary oxygen therapy in chronic hypoxic cor pulmonale complicating chronic bronchitis emphysema. Lancet 1981; i: 681-686.

14. Traver GA, Cline MG, Burrows B. Predictors of mortality in COPD. Am Rev Respir Dis 1979; 119: $895-902$.

15. Anthonisen NR. The Lung Health Study: effects of smoking intervention and the use of an inhaled anticholinergic bronchodilator on the rate of decline of FEV1. JAMA 1994; 272: $1497-1505$.

16. Henningfield JE. Nicotine medications for smoking cessation. New Engl J Med 1995; 2: 1196-1203.

17. Bucknall CE, Robertson C, Moran F, Stevenson RD. Differences in hospital asthma management. Lancet 1988; i: $748-750$.

18. Pearson MG, Ryland I, Harrison BDW. Comparison of the process of care of acute severe asthma in adults adjmitted to hospital before and $1 \mathrm{yr}$ after the publication of national guidelines. Respir Med 1996; 90: $539-545$.

19. Mant J, Hicks N. Detecting differences in quality of care: how sensitive are process and outcome measures in the treatment of acute myocardial infarction? BMJ 1995; 311: 793-796.

20. Slack R, Bucknall CEEE. Readmission rates are associated with differences in the process of care in acute asthma. Qual in Health Care 1997; 6: $194-$ 198.

21. Crombie IK, Davies HTO. Beyond health outcomes: the advantages of measuring process. $J$ Eval Clin Pract 1998; 4: $31-38$.

22. Bucknall CE, Ryland I, Cooper A, Coutts I, Connoly CK, Pearson MG. National benchmarking as a support system for clinical governance. $J R$ Coll Phys Lond 2000; 34: 52-56. 